Article

\title{
Using RapidEye and MODIS Data Fusion to Monitor Vegetation Dynamics in Semi-Arid Rangelands in South Africa
}

\section{Andreas Tewes ${ }^{1,2, *}$, Frank Thonfeld ${ }^{1,3}$, Michael Schmidtt ${ }^{4}$, Roelof J. Oomen ${ }^{2}$, Xiaolin Zhu ${ }^{5}$, Olena Dubovyk ${ }^{1}$, Gunter Menz ${ }^{1,3}$ and Jürgen Schellberg ${ }^{1,2}$}

1 Center for Remote Sensing of Land Surfaces, University of Bonn, Walter-Flex-Str. 3, 53113 Bonn, Germany; E-Mails: frank.thonfeld@uni-bonn.de (F.T.); odubovyk@uni-bonn.de (O.D.); g.menz@geographie.uni-bonn.de (G.M.); j.schellberg@uni-bonn.de (J.S.)

2 Institute of Crop Science and Resource Conservation (INRES), University of Bonn, Katzenburgweg 5, 53115 Bonn, Germany; E-Mail: roelof.oomen@uni-bonn.de

3 Remote Sensing Research Group, Department of Geography, University of Bonn, Meckenheimer Allee 166, 53115 Bonn, Germany

4 Remote Sensing Centre, Environment and Resource Sciences, Department of Science, Information Technology, Innovation and the Arts, GPO Box 5078, Brisbane, Queensland 4001, Australia;

E-Mail: michael.schmidt@science.dsitia.qld.gov.au

5 Ecosystem Science and Sustainability, Colorado State University, NESB 108, 1499 Campus Delivery, Fort Collins, CO 805239, USA; E-Mail: xiaolin.zhu@colostate.edu

* Author to whom correspondence should be addressed; E-Mail: atewes@uni-bonn.de; Tel.: +49-228-732-044; Fax: +49-228-732-870.

Academic Editors: Clement Atzberger and Prasad S. Thenkabail

Received: 2 September 2014 / Accepted: 7 April 2015 / Published: 26 May 2015

\begin{abstract}
Image time series of high temporal and spatial resolution capture land surface dynamics of heterogeneous landscapes. We applied the ESTARFM (Enhanced Spatial and Temporal Adaptive Reflectance Fusion Model) algorithm to multi-spectral images covering two semi-arid heterogeneous rangeland study sites located in South Africa. MODIS $250 \mathrm{~m}$ resolution and RapidEye $5 \mathrm{~m}$ resolution images were fused to produce synthetic RapidEye images, from June 2011 to July 2012. We evaluated the performance of the algorithm by comparing predicted surface reflectance values to real RapidEye images. Our results show that ESTARFM predictions are accurate, with a coefficient of determination for the red band $0.80<\mathrm{R}^{2}<0.92$, and for the near-infrared band $0.83<\mathrm{R}^{2}<0.93$, a mean relative bias between $6 \%$ and $12 \%$ for the red band and $4 \%$ to $9 \%$ in the near-infrared band.
\end{abstract}


Heterogeneous vegetation at sub-MODIS resolution is captured adequately: A comparison of NDVI time series derived from RapidEye and ESTARFM data shows that the characteristic phenological dynamics of different vegetation types are reproduced well. We conclude that the ESTARFM algorithm allows us to produce synthetic remote sensing images at high spatial combined with high temporal resolution and so provides valuable information on vegetation dynamics in semi-arid, heterogeneous rangeland landscapes.

Keywords: RapidEye; MODIS; ESTARFM; image fusion; data blending; vegetation dynamics; high spatial and temporal resolution; time series

\section{Introduction}

Time series of vegetation indices derived from remotely sensed data are readily used to monitor spatial and temporal dynamics of biophysical variables such as Leaf Area Index (LAI) or fraction of absorbed photosynthetically active radiation (fAPAR) [1,2], and phenological metrics such as day of green-up and duration of greenness [3]. Multi-temporal measurements of those variables provide information for spatially distributed environmental modelling across different scales, e.g., for yield forecasts, ecohydrologic cycles or land cover change [4].

Ecological studies often rely solely on field data, whose collection is time-consuming, cost-intensive and often limited in space and time. Remote sensing data play a supporting role, but only match poorly with small scale field measurements due to discrepancies in spatial resolution between the images and field data [5]. Furthermore, in-field ground truth measurements are hard to compare to remotely sensed data. Relevant processes may display a small-scale heterogeneity (e.g., spatially varying grazing intensities or heterogeneous abiotic site conditions [6]) that a selective sampling of species may not capture. Remotely sensed data exhibiting both high temporal and high spatial resolution show great promise for the exploration of processes taking place rapidly at scales similar to that of field assessments. Such data are available from different sensors like IKONOS, Quickbird, RapidEye or SPOT at over-flight intervals from 1 to 5 days. However, these data are costly and may have disadvantages for mapping on medium to large scales due to a small image footprint or limited spectral resolution [7]. A variety of studies have instead relied on using the mid-resolution Landsat sensors. For all optical satellites, the continuous temporal data coverage can be interrupted by clouds, cloud shadows, haze or smoke from fires [7,8]. The above-mentioned factors limit the use of remotely sensed data for detection of rapid surface changes, including spatial and temporal changes in vegetated surfaces [9]. Medium to low spatial resolution instruments such as MODIS, SPOT-Vegetation and AVHRR cover the earth on a daily basis over a wide field of view. This frequency is suitable for monitoring land cover dynamics at large scales [10]. Spatial resolution ranges from $250 \mathrm{~m}$ to $1000 \mathrm{~m}$, which is however not satisfactory for tracking changes (such as vegetation dynamics) and spatio-temporal patterns at ecologically relevant resolutions, especially in heterogeneous landscapes $[11,12]$.

Fusion of remotely sensed data from different sensors with different spatial and temporal characteristics is an efficient solution to enhance the capability of remote sensing for the monitoring of land surface dynamics at varying scales [12,13]. Pohl and Van Genderen [14] define image fusion as 
"the combination of two or more different images to form a new image by using a certain algorithm". It promotionally blends multiple registered images having disparate and distinct yet complementary attributes. Image fusion aims at enhancing information included in the images and at improving reliability of the prediction. The outcome mitigates or exceeds the limitations of each dataset used as input $[10,14]$. The result may be a combined time series that exhibits both a high temporal and high spatial resolution [8]. There are numerous scientific papers suggesting the fusion of data from multiple sensors to provide both high spatial and high temporal resolution $[4,15]$. However, only few studies suggest techniques that compute calibrated outputs of spectral radiance or reflectance values, which is required to study vegetation dynamics or quantitative changes in reflectance over time $[9,11]$.

Gao et al. [9] developed STARFM (Spatial and Temporal Adaptive Reflectance Fusion Model) to combine the spatial resolution of Landsat imagery with the temporal resolution of coarse-resolution sensors. A synthetic surface reflectance product at Landsat spatial resolution and high temporal resolution is obtained by combining spatial information from Landsat imagery and temporal information from coarse-resolution imagery. STARFM achieves good results if non-mixed coarse-resolution pixels exist in the area of application (i.e., homogeneous, large land cover patches). However, performance deteriorates in complex mixtures of small patched land cover types such as small-scale agriculture [9]. Several studies successfully tested the fusion of Landsat and MODIS in different environments [8,10,11,16-19].

Zhu et al. [12] developed the ESTARFM (Enhanced Spatial and Temporal Reflectance Fusion Model) algorithm to improve this shortcoming of the original STARFM method, by using the observed reflectance trend between two points in time, combined with the spectral unmixing theory [20] to better predict reflectance in changing, heterogeneous landscapes. Results show that ESTARFM is capable of preserving spatial details better than STARFM. Emelyanova et al. [17] evaluated the performance of blending algorithms including STARFM and ESTARFM and found that ESTARFM performed better where/when spatial variance was dominant, whereas STARFM performed better under prevailing conditions of temporal variance.

Our motivation for this study was to find a method that overcomes the low temporal resolution of time series and yet yields high spatial resolution that enables to capture spatial heterogeneity in vegetation dynamics. To achieve this we used an image fusion algorithm that blends high spatial resolution RapidEye data and high temporal resolution MODIS data. ESTARFM was selected as the algorithm of choice because (1) it explicitly improves the fusion accuracy of images especially in heterogeneous landscapes, and preserves spatial details, (2) it can be used for sensors other than Landsat and MODIS, (3) it does not require ancillary land cover data, and (4) it is freely available [12,17]. We are not aware of any study on the fusion of RapidEye with a coarse-resolution sensor. The research questions underlying this study are:

1. Is the ESTARFM algorithm applicable for generating time series using the combination of RapidEye and MODIS?

2. Is a time series combining real RapidEye with ESTARFM-computed synthetic images appropriate for detecting highly dynamic vegetation changes at different small scale bush density classes in semi-arid rangelands in South Africa? 


\section{Material and Methods}

\subsection{The Study Area}

The study area is situated in the Northern Cape Province of South Africa and lies within the southern outreaches of the Kalahari (Figure 1). The landscape is a savannah biome, which covers about 1/3 of South Africa, including most of the far-northern part of the Northern Cape Province [21]. Vegetation cover comprises a woody layer of mainly seasonally deciduous trees and shrubs, especially various species of the genus Acacia, and a ground layer of annual and perennial grasses and some forbs [22,23]. The study area lies within the southern African summer rainfall zone (October-April). Winters are dry, with little to no precipitation. Mean annual precipitation is $423 \mathrm{~mm}$ with a coefficient of variation of $34 \%$ (calculated over 37 years). Low precipitation has favoured the use of land for pasture farming, since much of the land is unsuitable for crop cultivation [23]. Rainfall, fire and grazing are the three key driving forces for vegetation dynamics in the Kalahari ecosystem, as in many other semi-arid rangelands [22,24]. During the study time period, the area received $203 \mathrm{~mm}$ of precipitation (54\% less than the long-term average).

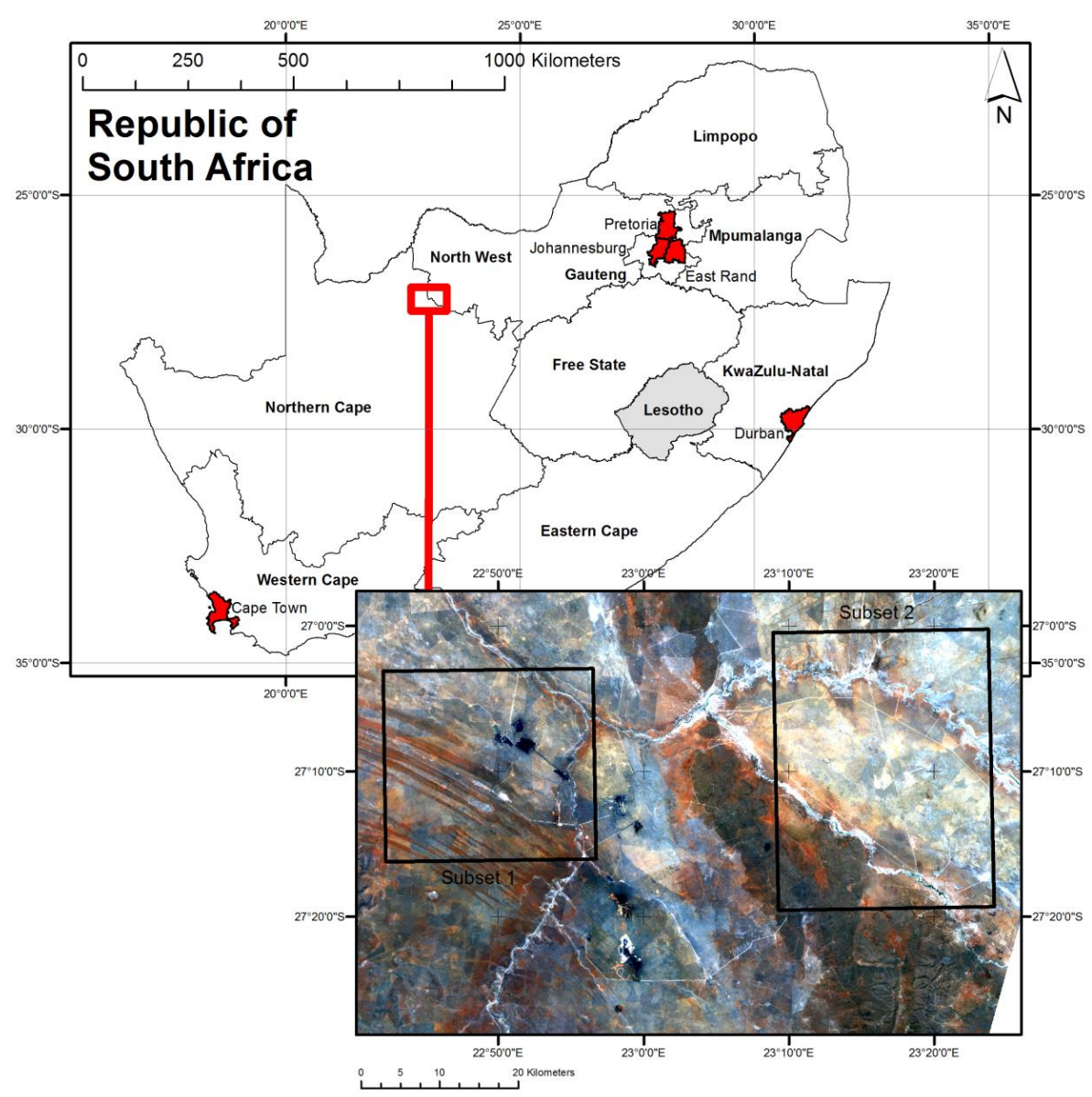

Figure 1. Location of study area. Subsets are indicated by black frames. The RapidEye image (true-colour RGB image using bands 3, 2 and 1) was acquired on 16 November 2011. Distinctive landmarks visible in the western part are sand dunes stretching from northwest to southeast and the Gamogara riverbed stretching from south to north. The eastern part shows the riverbed of Kuruman river stretching from west to east, and foothills of the Kuruman mountains stretching from southeast to northwest. 


\subsection{Data}

\subsubsection{The RapidEye Data}

The RapidEye system consists of 5 identical satellites placed in a single orbit. Each satellite carries a 5 band multi-spectral optical imager that captures radiation in the blue, green, red, red edge and near-infrared (NIR) spectral range. At nadir, ground sampling distance is $6.5 \mathrm{~m}$ and $5 \mathrm{~m}$ after orthorectification and resampling, respectively [25,26].

Twenty-three RapidEye images were used for our study. They were captured within the time period June 2011 to July 2012 (covering an entire vegetation growth cycle); with each scene not exceeding a cloud cover of $20 \%$. Eight images cover the study area in its entirety or for the most part, 15 images just partially (either eastern or western part of the study area). We formed 2 subsets for ESTARFM input to reduce data load and shorten image calculation routines. The western subset with an extent of $24 \mathrm{~km}$ by $24 \mathrm{~km}$ will be referred to as Subset 1, the eastern subset with an extent of $35 \mathrm{~km}$ by $24.5 \mathrm{~km}$ as Subset 2 . Their respective location is indicated as black frames in Figure 1. The RapidEye images were orthorectified and atmospherically corrected using the automated processing chain CATENA developed and maintained by the German Aerospace Center [27]. CATENA relies on the physical model implemented in the ATCOR software to eliminate atmospheric effects [28]. Clouds in RapidEye images were masked manually. Areas affected were assigned no-data values and excluded from further analysis. Table 1 shows that RapidEye and MODIS have corresponding spectral bands, except for RapidEye's Red Edge band at 690-730 $\mathrm{nm}$. The study area is crossed by both sensors within a narrow time frame (RapidEye: 9:25 am-9:45 am GMT, MODIS on Terra: 7:30 am-9:30 am GMT). Both instruments provide 12 bit radiometric sensitivity. RapidEye products are delivered with 16 bit unsigned integer bit depth, MODIS with 16 bit signed integer bit depth.

Table 1. RapidEye and MODIS band characteristics.

\begin{tabular}{ccccc}
\hline Band Name & \multicolumn{2}{c}{ Band No } & \multicolumn{2}{c}{ Spectral Range [nm] } \\
\hline & RapidEye & MODIS & RapidEye & MODIS \\
Blue & 1 & 3 & $440-510$ & $459-479$ \\
Green & 2 & 4 & $520-590$ & $545-565$ \\
Red & 3 & 1 & $630-685$ & $620-670$ \\
Red Edge & 4 & - & $690-730$ & - \\
NIR & 5 & 2 & $760-850$ & $841-876$ \\
\hline
\end{tabular}

\subsubsection{The MODIS Data}

To minimize the spatial resolution and acquisition time differences between the MODIS and RapidEye data, we selected the MOD09Q1 product. This product provides surface spectral reflectance as it would be measured at ground level in the absence of atmospheric scattering or absorption. It comprises bands 1 and 2 (red and NIR) on the Terra satellite at a $250 \mathrm{~m}$ resolution in an 8-day composite product, where each pixel contains the best possible observation during an 8-day period as selected on the basis of high observation coverage, low view angle, absence of clouds or cloud shadows, and aerosol loading ([29]). Additionally, each dataset contains a quality band that was used to assess the 
quality of each pixel. Higher likeliness to encounter cloud-free pixels and a reasonable trade-off between workload and temporal resolution of fused products were the reasons why we chose the 8-day composite product for our study. Missing MOD09Q1 data was substituted by the product MOD09GQ, which provides bands 1 and 2 at $250 \mathrm{~m}$ resolution in a daily gridded product. For visualization purposes, band 4 (green spectrum) was extracted from the MODIS product MOD09A1. This product is computed at the same dates as MOD09Q1 and provides bands 1 to 7 at $500 \mathrm{~m}$ resolution in an 8-day gridded product. The MOD09A1 product contains the same observations as MOD09Q1 in band 1 and 2 (according to Gao et al. [9], pixels are aggregated to $500 \mathrm{~m}$ resolution), respectively. By checking the quality band of every MODIS product, we found that all MODIS images were provided at best quality. To reduce algorithm computing time, sensor bands not suitable for the purpose of this study were excluded from the datasets. Accordingly, only red and NIR bands were included for NDVI calculation (for MODIS input either from MOD09Q1 or MOD09GQ), plus the green band. The MODIS data were re-projected to the UTM Zone 34 South using the USGS LP DAAC's MODIS Reprojection Tool Web Interface (MRTWeb) (https://mrtweb.cr.usgs.gov/). The implementation of ESTARFM requires MODIS data to be resampled to RapidEye $5 \mathrm{~m}$ resolution. No further processing was applied since the MODIS scenes were provided pre-corrected for atmospheric scattering and absorption. Co-registration of MODIS and RapidEye images was challenging because differences in spatial resolution were too large as to find reliable ground control points (GCPs). Visual inspection of 10 randomly selected MODIS and RapidEye images indicated a good overlay of distinguished landmarks, with none of the MODIS images requiring manual adjustment.

\subsection{The ESTARFM Algorithm}

The ESTARFM algorithm requires 2 pairs of fine-resolution and coarse-resolution images as input, with each pair ( $t_{1}$ and $t_{2}$ ) captured at the same date. For the desired prediction date $t_{\mathrm{p}}, 1$ coarse-resolution image is required. ESTARFM yields a synthetic image at the prediction date $t_{\mathrm{p}}$ with the same spatial resolution as the fine-resolution input images [12].

During the ESTARFM computation, four major steps take place: (1) Two fine-resolution images are used to search for pixels similar to the central pixel in a moving search window, (2) the spectral and spatial distance between each similar pixel and the predicted pixel are used to calculate weights of each similar pixel $w_{\mathrm{i}}$, (3) a linear regression of the coarse-resolution values in the two observed pairs ( $t_{1}$ and $\left.t_{2}\right)$ against the fine-resolution values of the similar pixel is used to determine the conversion coefficient $v_{\mathrm{i}}$, which is then used to convert the change found from the coarse-resolution images to the fine resolution images, and (4) fine-resolution reflectance from coarse-resolution image at prediction date $t_{\mathrm{p}}$, predicted as:

$$
F\left(x, y, t_{p}\right)=F\left(x, y, t_{0}\right)+\sum_{i=1}^{N} w_{i} \times v_{i} \times\left(C\left(x_{i}, y_{i}, t_{p}\right)-C\left(x_{i}, y_{i}, t_{o}\right)\right)
$$

Here, $F$ and $C$ represent fine-resolution image and coarse-resolution image reflectance, $(x, y)$ the location of the predicted pixel value while $x_{\mathrm{i}}$ and $y_{\mathrm{i}}$ is the location of $i$ th similar pixel, and $t_{0}$ is the date of 1 input pair $\left(t_{1}\right.$ or $\left.t_{2}\right) . N$ is the total number of similar pixels of the predicted pixel within a moving window. The algorithm is explained in detail in Zhu et al. [12]. 


\subsection{ESTARFM Implementation}

Synthetic images at RapidEye resolution were computed for both subsets using 14 RapidEye scenes captured between 28 June 2011 and 18 July 2012 as input (with 6 scenes covering both subsets and 4 composites each consisting of two scenes acquired within a short period of time, covering either subset), combined with the corresponding MODIS images acquired at the closest possible date (i.e., forming 10 image pairs; see Figure 2). The MOD09A1 day of the year layer was used to determine the acquisition day of the majority of pixels, aiming at minimizing the time difference between the MODIS and RapidEye observations. For image pair formation, 3 MODIS MOD09Q1 products were not available in 2012 (10 February 2012, 14 April 2012 and 11 July 2012); the daily surface reflectance product MOD09GQ was used instead. Here, the same acquisition date as of the corresponding RapidEye image was chosen. Coarse-resolution information at prediction dates $\left(t_{\mathrm{p}}\right)$ was provided by 39 (Subset 1) and 38 (Subset 2) MODIS images within the time period 04 July 2011 until 03 July 2012, respectively. For prediction, 3 missing MOD09Q1 datasets in 2012 (02 February 2012, 05 March 2012 and 21 March 2012) were substituted by MOD09GQ products. We chose the MODIS scene dated 14 April 2012 to only form an image pair with the RapidEye scene dated 19 April 2012 covering Subset 1, but not with the RapidEye scene acquired on 22 April 2012 (covering Subset 2) due to the major time lag. For this formation, we chose the MOD09GQ product of the same date instead and simultaneously used the scene for reflectance prediction of Subset 1 . The outcome of this is the different number of prediction dates. The second image pair (i.e., at date $t_{2}$ ) continuously served as first image pair in the next computation step (i.e., at date $t_{1}$ ). Two temporally closest image pairs were always provided as bracketing images for ESTARFM prediction. The size of the moving window was set to the size of one MODIS pixel, i.e., corresponding to $50 \times 50$ RapidEye pixels.

\subsection{Accuracy Assessment of ESTARFM Images}

The validation of the accuracy of the synthetic images was undertaken using a set of images independent from those that were used as ESTARFM input. Nine RapidEye scenes, each captured at a date bracketed by two consecutive RapidEye images used for ESTARFM processing, were used to compare pixel values in the predicted image with the corresponding pixels in the reference RapidEye image, on a band by band basis (following Walker et al. [10]). White and light grey coloured acquisition dates in Figure 2 indicate the image pairs used for cross-comparison. Prediction quality was assessed for the entire sub-scenes, independent from land cover type or vegetation cover. This yielded a sample size of 24 million to 34 million pixels per image pair, depending on extent and cloud cover. Only one RapidEye image (captured on 17 January 2012) covered the study area completely, the others either Subset 1 or Subset 2. The accuracy assessment of our study was based on a scheme proposed by Wald et al. [30] and Thomas and Wald [31]. We employed the following quantitative criteria:

1. The bias as well as its value relative to the mean value of the observed image should ideally be 0 . The bias is the difference between the mean value of the observed RapidEye and predicted ESTARFM image. 
2. The standard deviation of the difference image in relative value, i.e., divided by the mean of the reference image, should ideally be 0 . This measure indicates the level of error at any pixel, throughout the entire image (thus hereafter referred to as per-pixel level of error).

3. On a band by band basis, the coefficient of determination $\left(R^{2}\right)$ between the observed RapidEye and the synthetic ESTARFM image should be as close as possible to 1. This measures the pixel-wise similarity in the observed versus the predicted image.

\begin{tabular}{|c|c|c|c|}
\hline RapidEye & ESTARFM & MODIS & \\
\hline 2011-06-28 & & 2011-06-26 & 1 \\
\hline \multirow[t]{2}{*}{ 2011-07-17 } & 2011-07-12 & \multirow[b]{2}{*}{7 MOD09Q1 Images } & I \\
\hline & & & \\
\hline 2011-09-02 & & 2011-08-29 & 2 \\
\hline 2011-09-24 & 2011-09-22 & 4 MOD09Q1 Images & II \\
\hline 2011-10-09/12 & & 2011-10-08 & 3 \\
\hline 2011-10-31 & 2011-10-24 & 4 MOD09Q1 Images & III \\
\hline 2011-11-16 & & 2011-11-17 & 4 \\
\hline 2011-12-02 & 2011-11-25 & 2 MOD09Q1 Images & IV \\
\hline \multirow[t]{2}{*}{ 2011-12-16/17 } & & 2011-12-11 & 5 \\
\hline & & 1 MOD09Q1 Image & \\
\hline 2012-01-02 & & $2011-12-27$ & 6 \\
\hline 2012-01-17 & 2012-01-09 & $\begin{array}{l}4 \text { MOD09Q1, } \\
1 \text { MOD09GQ Images }\end{array}$ & $\mathbf{V}$ \\
\hline 2012-02-11 & & 2012-02-11 & 7 \\
\hline \multirow[t]{2}{*}{ 2012-03-03 } & 2012-02-26 & \multirow{3}{*}{$\begin{array}{l}5 \text { MOD09Q, } \\
2 \text { MOD09GQ Images }\end{array}$} & VI \\
\hline & & & \\
\hline \begin{tabular}{|l|} 
2012-04-09 \\
\end{tabular} & 2012-04-06 & & VII \\
\hline 2012-04-19/22 & & 2012-04-14/22 & 8 \\
\hline 2012-05-10 & 2012-04-30 & \multirow{2}{*}{$\begin{array}{l}3 \text { MOD09Q1, } \\
1 \text { MOD09GQ } \\
\text { (Western Part Only) } \\
\text { Images }\end{array}$} & VIII \\
\hline & & & \\
\hline 2012-05-26/27 & & 2012-05-24 & 9 \\
\hline & & \multirow{2}{*}{5 MOD09Q1 Images } & \\
\hline 2012-06-30 & 2012-06-25 & & IX \\
\hline 2012-07-18 & & 2012-07-18 & 10 \\
\hline
\end{tabular}

Type of data:

RapidEye

Synthetic ESTARFM Image

MODIS

Image Pair

\begin{tabular}{l|l} 
RapidEye & MODIS
\end{tabular}

Accuracy Assessment

RapidEye ESTARFM

Figure 2. Timeline of acquisition dates of RapidEye and MODIS scenes used for this study. MODIS MOD09Q1 product data come as an 8-day gridded product; the dates given in the figure are the first day of the 8-day period. For dates where the above-mentioned product was not available, the daily reflectance product MOD09Q1 was chosen, with the date equal to the correspondent RapidEye image acquisition date. Pairs used as ESTARFM input are indicated with Arabic numerals, pairs used for the accuracy assessment with Roman numerals.

\subsection{Bush Density Information}

The reflectance differences $\Delta \rho$, measured by RapidEye and by MODIS in a given pixel location $(x, y)$ for band $B$ are composed of the orbit parameters, the location and spectral range of the bands, the 
acquisition time (implying different sun illumination angles), the different atmospheric correction approaches, the viewing angles, the overlay (co-registration of images) and the spatial resolution of the sensor, resulting in pixels that are composed of a variety of reflectances. While it is difficult to investigate the influence of the separate components, the factor of spatial resolution may be analysed based on the following thoughts: One MODIS pixel exhibiting a spatial resolution of $250 \mathrm{~m}$ contains the average reflectance of all land cover types contained therein, whereas the RapidEye sensor is capable of dissolving these into 2500 different values $(50 \times 50$ RapidEye pixels, perfect overlay given). Such high spatial resolution allows for better vegetation classification, and so determines the proportions of land cover each MODIS pixel is composed of. One basis for vegetation classification is the temporal behaviour of composited NDVI (Normalized Difference Vegetation Index) time series. Vegetation phenology shows distinct seasonal patterns in semi-arid savannahs since growth is water-limited [32]. This applies for both the bush and grass layer. According to Scholes and Walker [33], trees and bushes in southern African savannahs exhibit signs of growth before the first "effective" rainfall due to their ability to access subsurface moisture, whereas grasses respond to rainfall events and exhibit a shorter, more intensive growth pulse.

The widely utilized unsupervised $k$-means cluster algorithm was used to classify the composited NDVI time series, derived from 15 (Subset 1) and 16 (Subset 2) RapidEye images used within our study (i.e., comprising RapidEye images used for algorithm input and for accuracy assessment). Large areas not used as rangeland were masked and excluded from the classification and further study.

Clusters found by the algorithm were identified using expert knowledge and the above mentioned orthophotos, and subsequently merged into the user-defined vegetation type classes "grass cover" or "bush cover" or the type "asphalt, bare soil, non-dynamic surface" for non-vegetated areas. We then calculated the percentage area classified as "bush cover" falling into each MODIS pixel at $250 \mathrm{~m}$ resolution. Those areas at MODIS pixel resolution that intersected with the class "asphalt, bare soil, non-dynamic surface" were excluded to reduce the error of interfering signals. On a band by band basis, the coefficient of determination $R^{2}$ between the observed RapidEye and predicted ESTARFM images was calculated for every bush density class, thereby determining the prediction accuracy at sub-MODIS scale.

\subsection{Monitoring Vegetation Dynamics}

Despite its appearance to be a poor indicator of vegetation biomass for low ground cover, a number of studies confirm the usefulness of NDVI for monitoring vegetation dynamics in arid and semi-arid environments (e.g., Schmidt and Karnieli [34]; Weiss et al. [35]). To investigate the usability of ESTARFM for vegetation monitoring purposes, parallel time series of the Normalized Difference Vegetation Index (NDVI) were computed based solely on RapidEye, MODIS and ESTARFM images for the different bush density classes.

\section{Results}

\subsection{ESTARFM Prediction Results}

The ESTARFM algorithm yielded 77 synthetic images (39 images for Subset 1, 38 images for Subset 2) at RapidEye resolution, covering the time period June 2011 until July 2012 (Figure 2). Figure 3 shows 
an exemplary comparison of the images. Visual inspection revealed that spatial details are kept well by ESTARFM, including areas with heterogeneous land cover, differing vegetation or distinct land forms.

Figure 4 shows scatter plots that represent per-pixel comparisons between the observed RapidEye and predicted ESTARFM images used for the accuracy assessment as illustrated in Figure 2. A random sample consisting of $10 \%$ of all pixels was drawn from each scene. The analysis was performed on all of the 9 validation pairs. For the ease of presentation, we have selected examples from different dates. Please note that, contrary to all other RapidEye images, the scene captured on 17 January 2012 covers the entire study area. Thus, an accuracy assessment of the predicted ESTARFM images for both subsets was possible (plots E-H).

The relationship between the observed and predicted pixel values shows a close adherence to the 1:1 line in all cases in both the red and NIR band, proving that reflectance is accurately predicted by ESTARFM for each image. The slopes of the regression lines range from 0.79 to 0.98 for the red band and from 0.76 to 1.0 for the NIR band. This indicates only little differences between the observed and predicted images. Extreme outlying pixels were checked and visually compared to orthophotos. We found that in most cases outliers resulted from single pixels displaying objects exhibiting high reflectance, such as corrugated sheet roofs or patches of bare bright rocks and sand. Parts of the scatter plots (E), (F) and (H) deviate downwards from the 1:1 line, indicating lower predicted pixel values than actually observed. Affected pixels mainly comprise vegetated areas, suggesting phenological changes between beginning of January and middle of February 2012 that were not well captured by ESTARFM. Table 2 shows the pixel-based, band by band results of the accuracy assessments for the two subsets. Here, the relative mean bias is normalized to the observed reflectance of each band, thus facilitates a comparison between the different wavelengths. A value of 0.1 for instance indicates that the predicted image overestimated the mean reflectance in the observed image by $10 \%$ [11]. ESTARFM both under-and overestimated mean reflectance in the red and NIR band, commonly between 0 and $16 \%$. The most apparent difference among the results, evaluated on the basis of the acquisition dates, is the relatively poor performance of the image predicted for 24 October 2011. The mean reflectance for the corresponding RapidEye image of 31 October 2011 is underestimated by $39 \%$ in the red and $40 \%$ in the NIR band, with high values of the absolute mean bias (red: 656.42, NIR: 1102.68).

Correlation is high-Indicating a very strong relationship (red: 0.88, NIR: 0.89)—And the scatter plot (Figure 4C,D) does not show strong deviations from the 1:1 line. It arises from the accuracy assessment for the predicted image on 09 January 2012 that ESTARFM underestimates the mean reflectance in the red band by $7 \%$, whereas NIR reflectance is overestimated by $2 \%$. Generally, better prediction results were found for the NIR bands than for the red bands. Per-pixel levels of error vary between 0.06 and 0.012 (standard deviation of $6 \%$ to 12\%) for the red band and between 0.04 and 0.08 for the NIR band, also indicating a better performance of ESTARFM in the longer waveband. Correlation between observed and predicted images is generally high. For all dates, the NIR band yielded better results than the red band (Red: $0.80<\mathrm{R}^{2}<0.92$, NIR: $0.83<\mathrm{R}^{2}<0.93$ ). Prediction accuracy was lowest for the scene predicted for 17 January 2012 (which also shows strong deviations downwards from the 1:1 line in the scatter plot, Figure $4 \mathrm{E}-\mathrm{H}$ ), while precision improves for the antecedent and precedent scenes, with the best results found for the scenes predicted for 24 September 2011 and 30 June 2012. 

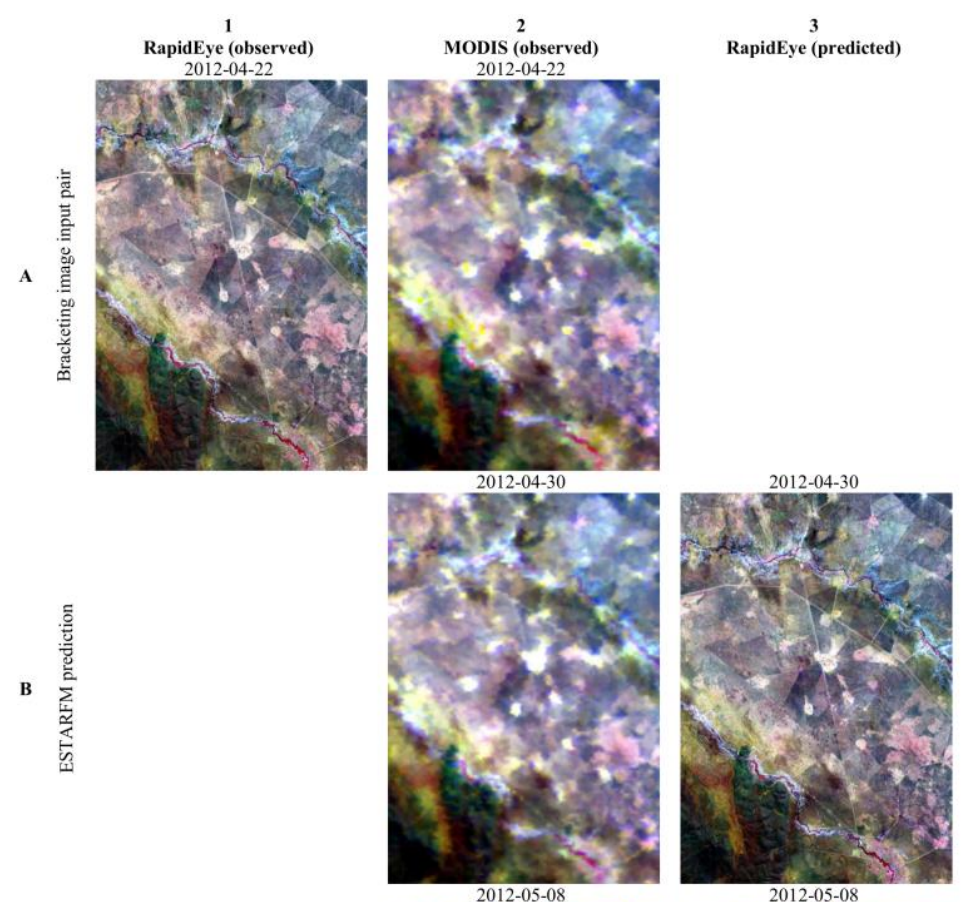

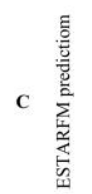
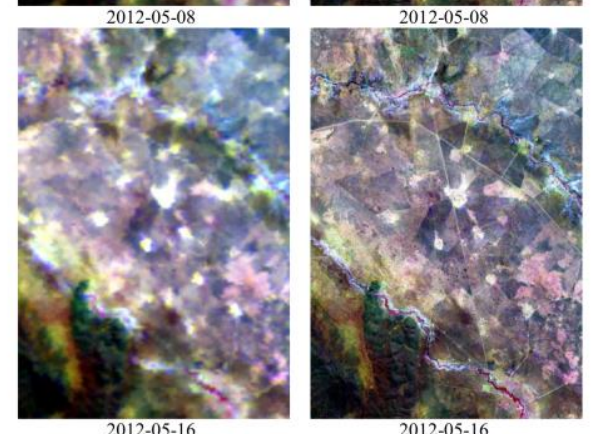

D)
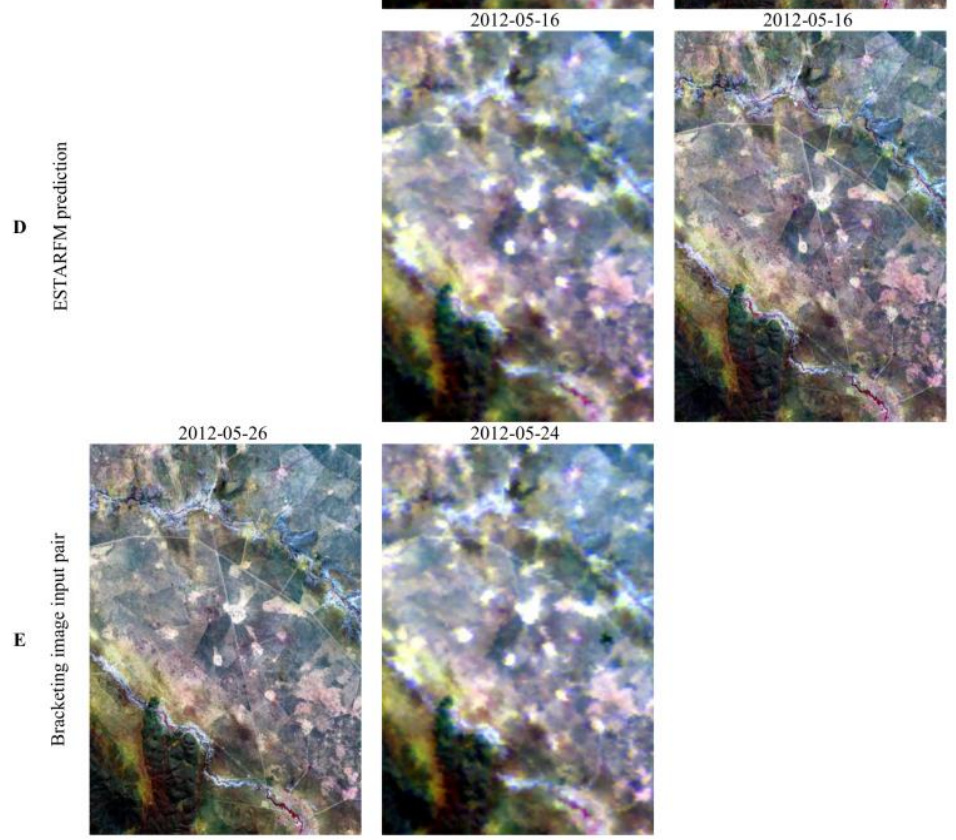

Figure 3. Exemplary comparison between observed RapidEye scenes (left column), observed MODIS scenes (central column), and ESTARFM predicted RapidEye scenes (right column) for Subset 2 for 3 acquisition dates in April and May 2012. First and last row $(\mathrm{A}, \mathrm{E})$ show images used as bracketing pairs $t_{1}$ and $t_{2}$. All images are shown as false-colour datasets (NIR-Red-Green). 

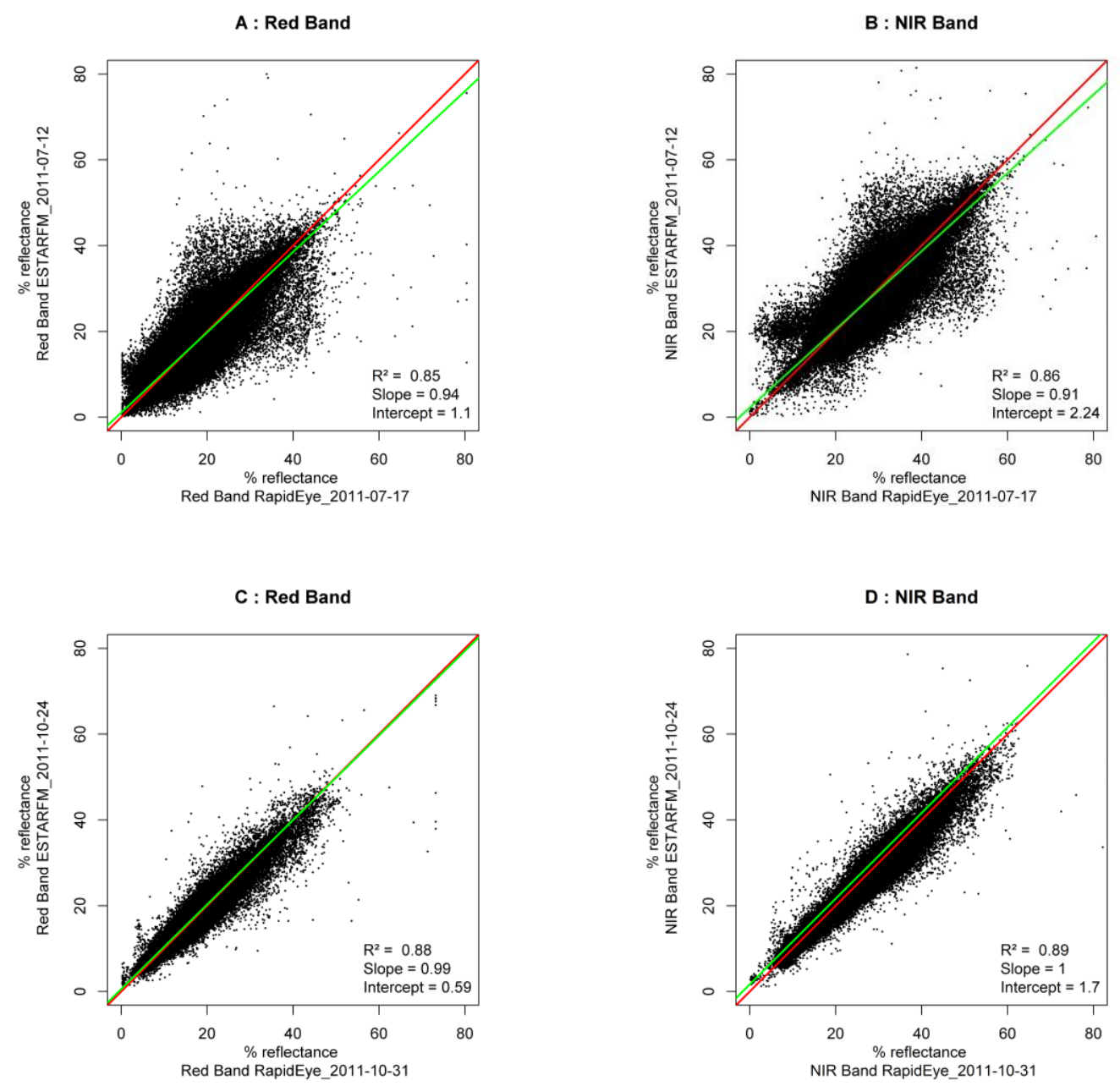

E : Red Band
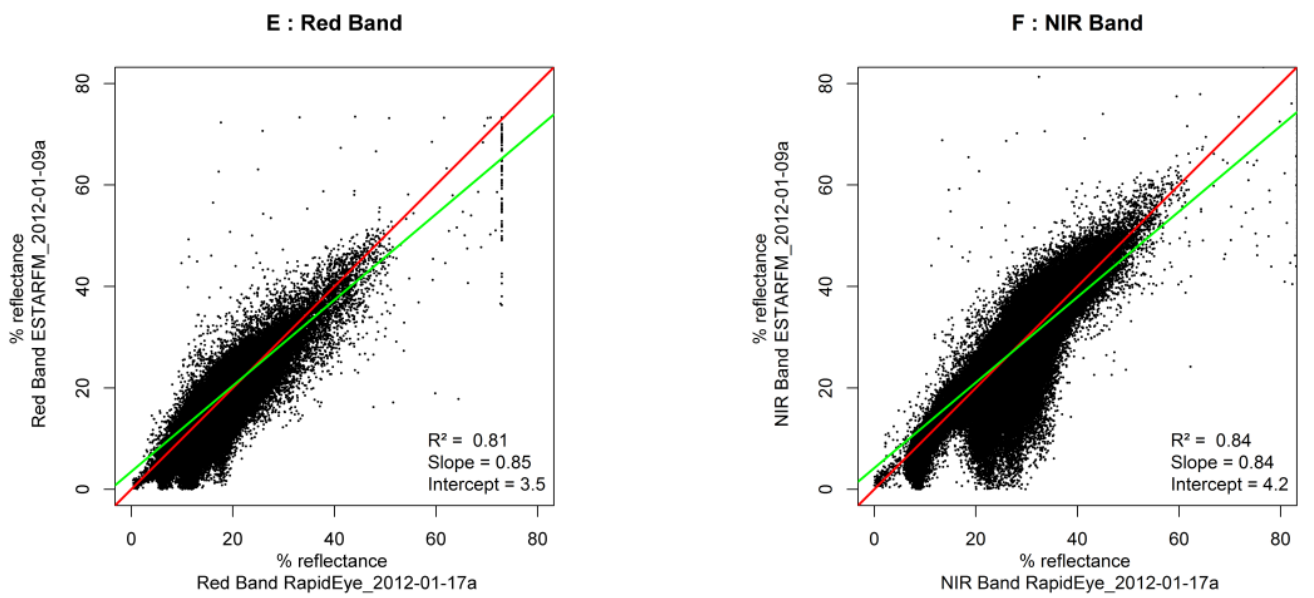

Figure 4. Cont. 


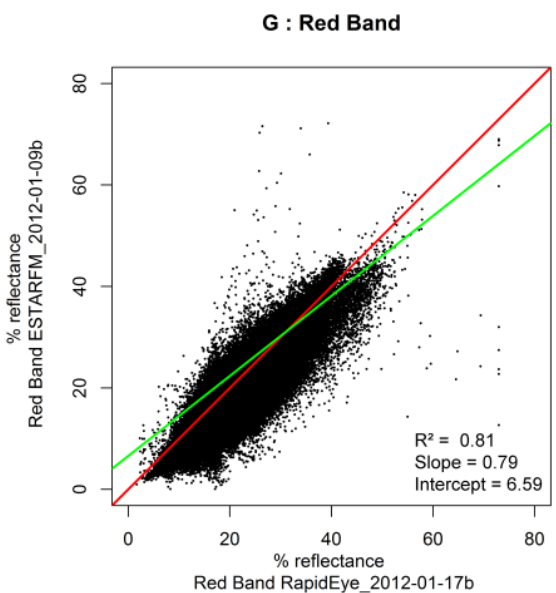

I : Red Band

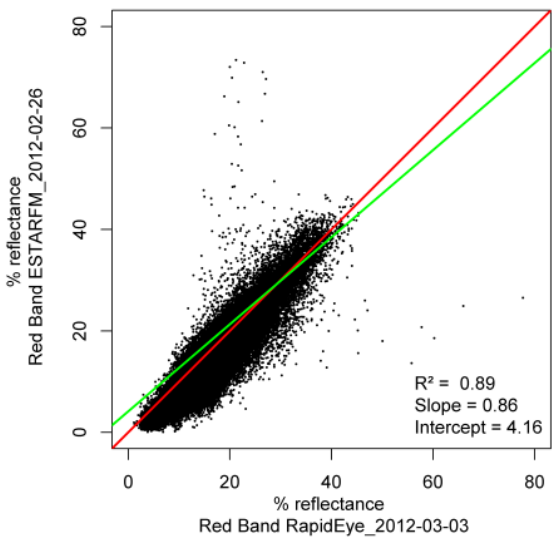

$K$ : Red Band

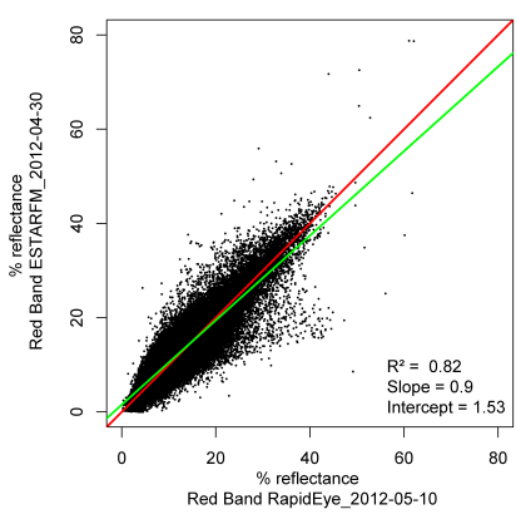

H : NIR Band

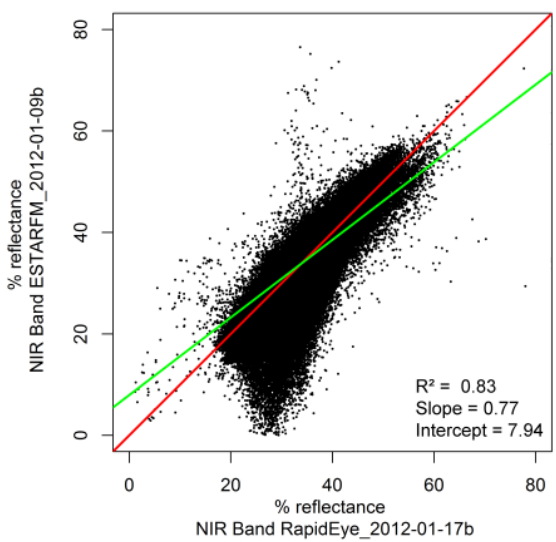

$J$ : NIR Band

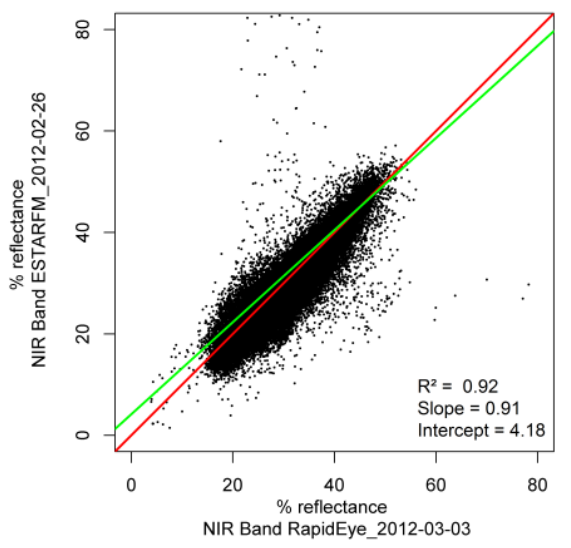

L : NIR Band

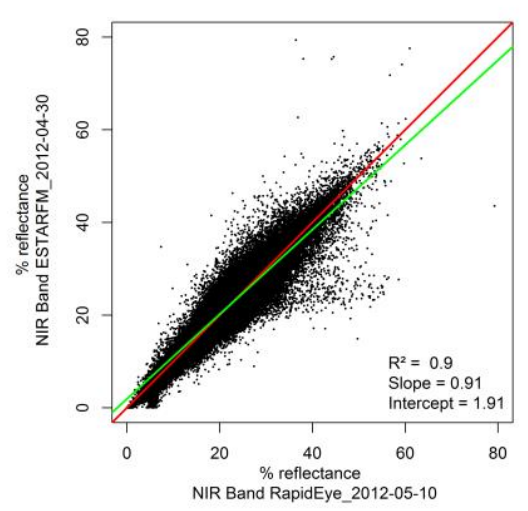

Figure 4. Per-pixel comparison between observed and predicted RapidEye reflectance for the assessment pairs as listed in Figure 2. The 1:1 line is shown in red, the regression line in green. Plots (left column) illustrate the reflectance values for the red band, plots (right column) the values for the NIR band. The $\mathrm{x}$-axis displays the values of the respective RapidEye image, the $\mathrm{y}$-axis the values of the correspondent predicted ESTARFM image. 
Table 2. Results for the pixel-based, band by band accuracy assessment of the RapidEye images against the ESTARFM computed predicted images. Numbers are rounded. Subset 1 has a sample size of 23,072,682 pixels, Subset 2 a size of 34,592,816 pixels. The Absolute Mean Bias is given in surface reflectance units.

\begin{tabular}{|c|c|c|c|c|c|c|c|}
\hline RapidEye & MODIS & Subset & Band & $\begin{array}{c}\text { Absolute } \\
\text { Mean Bias }\end{array}$ & $\begin{array}{c}\text { Relative } \\
\text { Mean Bias }\end{array}$ & $\begin{array}{c}\text { Per-Pixel Level } \\
\text { of Error }\end{array}$ & $\mathbf{R}^{2}$ \\
\hline \multirow{2}{*}{ 17-07-2011 } & \multirow{2}{*}{$12-07-2011$} & \multirow{2}{*}{2} & Red & -14.18 & -0.01 & 0.12 & 0.85 \\
\hline & & & NIR & -2.15 & 0.00 & 0.08 & 0.86 \\
\hline \multirow{2}{*}{ 24-09-2011 } & \multirow{2}{*}{ 22-09-2011 } & \multirow{2}{*}{2} & Red & 43.82 & 0.03 & 0.07 & 0.91 \\
\hline & & & NIR & 19.05 & 0.01 & 0.04 & 0.93 \\
\hline \multirow{2}{*}{$31-10-2011$} & \multirow{2}{*}{ 24-10-2011 } & \multirow{2}{*}{1} & Red & -656.42 & -0.39 & 0.06 & 0.88 \\
\hline & & & NIR & -1102.68 & -0.40 & 0.05 & 0.89 \\
\hline \multirow{2}{*}{ 02-12-2011 } & \multirow{2}{*}{$25-11-2011$} & \multirow{2}{*}{1} & Red & 118.9 & 0.07 & 0.07 & 0.87 \\
\hline & & & NIR & 161.42 & 0.06 & 0.05 & 0.92 \\
\hline \multirow{2}{*}{$17-01-2012 \mathrm{a}$} & \multirow{2}{*}{$09-01-2012 \mathrm{a}$} & \multirow{2}{*}{1} & Red & -115.52 & -0.07 & 0.09 & 0.80 \\
\hline & & & NIR & 52.47 & 0.02 & 0.07 & 0.84 \\
\hline \multirow{2}{*}{$17-01-2012 b$} & \multirow{2}{*}{$09-01-2012 b$} & \multirow{2}{*}{2} & Red & -295.36 & -0.15 & 0.10 & 0.81 \\
\hline & & & NIR & -31.98 & -0.01 & 0.07 & 0.83 \\
\hline \multirow{2}{*}{ 03-03-2012 } & \multirow{2}{*}{ 26-02-2012 } & \multirow{2}{*}{2} & Red & -240.98 & -0.16 & 0.09 & 0.89 \\
\hline & & & NIR & -173.41 & -0.06 & 0.05 & 0.92 \\
\hline \multirow{2}{*}{ 09-04-2012 } & \multirow{2}{*}{ 06-04-2012 } & \multirow{2}{*}{2} & Red & -139.35 & -0.10 & 0.10 & 0.89 \\
\hline & & & NIR & -190.03 & -0.07 & 0.05 & 0.92 \\
\hline \multirow{2}{*}{$10-05-2012$} & \multirow{2}{*}{ 30-04-2012 } & \multirow{2}{*}{1} & Red & -40.25 & -0.04 & 0.11 & 0.82 \\
\hline & & & NIR & -9.63 & 0.00 & 0.06 & 0.90 \\
\hline \multirow{2}{*}{$30-06-2012$} & \multirow{2}{*}{$25-06-2012$} & \multirow{2}{*}{2} & Red & 21.6 & 0.01 & 0.09 & 0.91 \\
\hline & & & NIR & 92.57 & 0.04 & 0.05 & 0.92 \\
\hline
\end{tabular}

\subsection{Analysis of Reflectances Time Series}

Time series of MODIS, RapidEye and ESTARFM reflectance for red and NIR bands are shown in Figure 5. Each time series represents average values for each date of an image observation and image subset. Only those pixels falling into MODIS pixels containing less than 5\% of bush cover (i.e., with grass as the main ground cover) were considered. We chose this approach to select relatively homogeneous areas large enough to compare the time series directly, assuming that these areas exhibit "pure", comparable signals. The RapidEye time series consists of both the images used for the fusion process and the ones used in the accuracy assessment. The general behaviour of the ESTARFM and the RapidEye time series in both subsets aligns well for both the red and NIR band. MODIS observations have a strong influence on the ESTARFM predictions. Amplitudes of the ESTARFM curves are highest when the offset between MODIS and RapidEye bracketing images is little and constant, and MODIS images used for prediction simulate a sharp increase or decrease in reflectance, whereas the RapidEye suggests only a moderate change. The MODIS time series exhibit an unexpected oscillating pattern within the seasonal curve, with sharp amplitudes in December and January 2012. The RapidEye time series do not show this feature, but a rather uniform increase over extended periods of time. 
Tables 3 and 4 compare observed RapidEye and predicted ESTARFM images for the red and NIR bands, summarized for the bush cover classes and the study area subset, respectively. As already observed in the accuracy assessment conducted for the entire scenes, by the majority the coefficient of determination between observed and predicted images is higher for the NIR band than for the red band. $R^{2}$ values are generally lower than those found in the accuracy assessment. Scenes of low prediction accuracy in the assessment also show low correlation values in the bush cover classification.
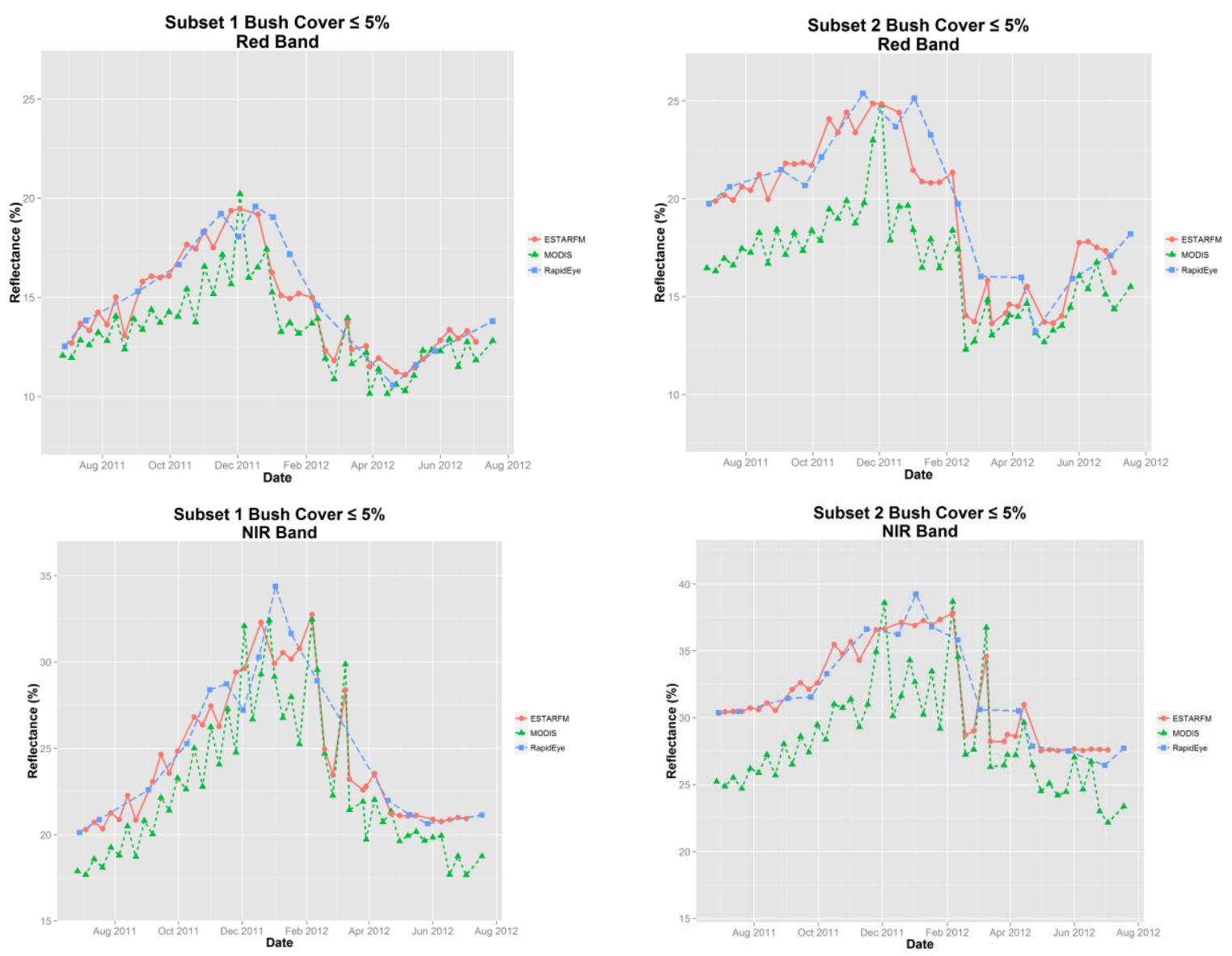

Figure 5. Time series of MODIS (green), RapidEye (blue) and ESTARFM (red) reflectance for the red (left column) and near-infrared (right column) band for those pixels falling into MODIS pixel size extents classified as "Less than 5\% bush density".

Table 3. Pixel based regression of the observed RapidEye scenes against the correspondent ESTARFM predicted images for Subset 1, summarized for bush cover classes. The bias is given as its value relative to the mean value of the observed image. Numbers in brackets show number of pixels at RapidEye resolution.

\begin{tabular}{cccccccccc}
\hline Bush Density & Band & \multicolumn{10}{c}{ Date } \\
\hline & & $\mathbf{3 1 - 1 0 - 2 0 1 1}$ & $\mathbf{0 2 - 1 2 - 2 0 1 1}$ & $\mathbf{1 7 - 0 1 - 2 0 1 2}$ & $\mathbf{1 0 - 0 5 - 2 0 1 2}$ \\
\hline & & $\mathbf{R}^{\mathbf{2}}$ & Bias & $\mathbf{R}^{\mathbf{2}}$ & Bias & $\mathbf{R}^{\mathbf{2}}$ & Bias & $\mathbf{R}^{\mathbf{2}}$ & Bias \\
\hline$\leq 5 \%$ & Red & 0.70 & -0.05 & 0.79 & 0.07 & 0.83 & -0.12 & 0.71 & -0.04 \\
$(79,354)$ & NIR & 0.75 & -0.04 & 0.87 & 0.08 & 0.83 & -0.03 & 0.88 & 0.00 \\
\hline
\end{tabular}


Table 3. Cont.

\begin{tabular}{ccccccccccc}
\hline Bush Density & Band & \multicolumn{10}{c}{ Date } \\
\hline & & $\mathbf{3 1 - 1 0 - 2 0 1 1}$ & $\mathbf{0 2 - 1 2 - 2 0 1 1}$ & $\mathbf{1 7 - 0 1 - 2 0 1 2}$ & $\mathbf{1 0 - 0 5 - 2 0 1 2}$ \\
\hline & & $\mathbf{R}^{\mathbf{2}}$ & Bias & $\mathbf{R}^{\mathbf{2}}$ & Bias & $\mathbf{R}^{\mathbf{2}}$ & Bias & $\mathbf{R}^{2}$ & Bias \\
\hline$>5 \%, \leq 20 \%$ & Red & 0.74 & -0.04 & 0.83 & 0.06 & 0.69 & -0.08 & 0.73 & -0.08 \\
\cline { 2 - 11 }$(356,336)$ & NIR & 0.82 & -0.07 & 0.90 & 0.06 & 0.74 & -0.01 & 0.87 & 0.01 \\
\hline$>20 \%, \leq 35 \%$ & Red & 0.76 & -0.03 & 0.85 & 0.06 & 0.60 & -0.07 & 0.77 & -0.08 \\
$(569,186)$ & NIR & 0.83 & -0.06 & 0.91 & 0.05 & 0.70 & 0.01 & 0.88 & 0.01 \\
\hline$>35 \%, \leq 50 \%$ & Red & 0.77 & -0.03 & 0.85 & 0.07 & 0.62 & -0.09 & 0.80 & -0.07 \\
$(553,589)$ & NIR & 0.79 & -0.07 & 0.89 & 0.05 & 0.74 & 0.01 & 0.90 & 0.00 \\
\hline$>50 \%, \leq 65 \%$ & Red & 0.82 & -0.03 & 0.85 & 0.07 & 0.70 & -0.09 & 0.77 & -0.06 \\
$(634,875)$ & NIR & 0.86 & -0.07 & 0.90 & 0.05 & 0.82 & 0.01 & 0.89 & 0.00 \\
\hline$>65 \%, \leq 80 \%$ & Red & 0.84 & -0.03 & 0.86 & 0.07 & 0.72 & -0.10 & 0.78 & -0.06 \\
$(862,093)$ & NIR & 0.86 & -0.07 & 0.91 & 0.05 & 0.82 & 0.01 & 0.89 & 0.00 \\
\hline$>80 \%, \leq 95 \%$ & Red & 0.80 & -0.02 & 0.83 & 0.08 & 0.73 & -0.09 & 0.78 & -0.05 \\
$(1,620,701)$ & NIR & 0.82 & -0.06 & 0.90 & 0.05 & 0.83 & 0.02 & 0.87 & 0.00 \\
\hline$>95 \%$ & Red & 0.80 & -0.02 & 0.79 & 0.08 & 0.69 & -0.08 & 0.80 & -0.04 \\
$(27,787)$ & NIR & 0.86 & -0.07 & 0.90 & 0.05 & 0.86 & 0.03 & 0.86 & 0.00 \\
\hline
\end{tabular}

Table 4. Pixel based regression of the observed RapidEye scenes against the correspondent ESTARFM predicted images for Subset 2, summarized for bush cover classes. See Table 3 for further information.

\begin{tabular}{|c|c|c|c|c|c|c|c|}
\hline \multirow[t]{3}{*}{ Bush Density } & \multirow[t]{3}{*}{ Band } & \multicolumn{6}{|c|}{ Date } \\
\hline & & \multicolumn{2}{|c|}{ 17-07-2011 } & \multicolumn{2}{|c|}{ 24-09-2011 } & \multicolumn{2}{|c|}{ 17-01-2012 } \\
\hline & & $\mathbf{R}^{2}$ & Bias & $\mathbf{R}^{2}$ & Bias & $\mathbf{R}^{2}$ & Bias \\
\hline \multirow{2}{*}{$\begin{array}{c}\leq 5 \% \\
(375,469)\end{array}$} & Red & 0.58 & -0.02 & 0.73 & 0.06 & 0.47 & -0.10 \\
\hline & NIR & 0.68 & 0.00 & 0.79 & 0.02 & 0.53 & 0.01 \\
\hline \multirow{2}{*}{$\begin{array}{c}>5 \%, \leq 20 \% \\
(903,438)\end{array}$} & Red & 0.67 & -0.02 & 0.81 & 0.05 & 0.55 & -0.10 \\
\hline & NIR & 0.75 & 0.00 & 0.86 & 0.01 & 0.55 & 0.01 \\
\hline \multirow{2}{*}{$\begin{array}{c}>20 \%, \leq 35 \% \\
(884,540)\end{array}$} & Red & 0.66 & -0.01 & 0.81 & 0.04 & 0.59 & -0.10 \\
\hline & NIR & 0.74 & 0.00 & 0.85 & 0.01 & 0.60 & 0.01 \\
\hline \multirow{2}{*}{$\begin{array}{c}>35 \%, \leq 50 \% \\
(725,780)\end{array}$} & Red & 0.66 & -0.01 & 0.81 & 0.04 & 0.59 & -0.11 \\
\hline & NIR & 0.73 & 0.00 & 0.85 & 0.01 & 0.53 & 0.00 \\
\hline \multirow{2}{*}{$\begin{array}{c}>50 \%, \leq 65 \% \\
(838,079)\end{array}$} & Red & 0.64 & -0.01 & 0.79 & 0.03 & 0.64 & -0.12 \\
\hline & NIR & 0.73 & 0.00 & 0.84 & 0.01 & 0.58 & 0.00 \\
\hline \multirow{2}{*}{$\begin{array}{c}>65 \%, \leq 80 \% \\
(963,657) \\
\end{array}$} & Red & 0.62 & -0.01 & 0.77 & 0.03 & 0.60 & -0.13 \\
\hline & NIR & 0.71 & 0.00 & 0.82 & 0.00 & 0.53 & 0.00 \\
\hline \multirow{2}{*}{$\begin{array}{c}>80 \%-\leq 95 \% \\
(1,098,853)\end{array}$} & Red & 0.57 & -0.01 & 0.75 & 0.02 & 0.59 & -0.14 \\
\hline & NIR & 0.67 & 0.00 & 0.79 & 0.00 & 0.53 & 0.00 \\
\hline \multirow{4}{*}{$\begin{array}{c}>95 \% \\
(453,262) \\
\end{array}$} & Red & 0.57 & -0.01 & 0.63 & 0.02 & 0.56 & -0.19 \\
\hline & NIR & 0.63 & 0.00 & 0.62 & 0.01 & 0.48 & -0.04 \\
\hline & & \multicolumn{2}{|c|}{ 03-03-2012 } & \multicolumn{2}{|c|}{ 09-04-2012 } & \multicolumn{2}{|c|}{ 30-06-2012 } \\
\hline & & $\mathrm{R}^{2}$ & Bias & $\mathrm{R}^{2}$ & Bias & $\mathrm{R}^{2}$ & Bias \\
\hline \multirow{2}{*}{$\leq 5 \%$} & Red & 0.77 & -0.14 & 0.83 & -0.09 & 0.77 & 0.01 \\
\hline & NIR & 0.89 & -0.05 & 0.88 & -0.06 & 0.88 & 0.04 \\
\hline
\end{tabular}


Table 4. Cont.

\begin{tabular}{cccccccc}
\hline Bush Density & Band & \multicolumn{6}{c}{ Date } \\
\hline & & $\mathbf{1 7 - 0 7 - 2 0 1 1}$ & $\mathbf{2 4 - 0 9 - 2 0 1 1}$ & $\mathbf{1 7 - 0 1 - 2 0 1 2}$ \\
\hline \multirow{2}{*}{$>5 \%, \leq 20 \%$} & & $\mathbf{R}^{\mathbf{2}}$ & Bias & $\mathbf{R}^{\mathbf{2}}$ & Bias & $\mathbf{R}^{\mathbf{2}}$ & Bias \\
\hline \multirow{2}{*}{ 20\%, $\leq 35 \%$} & Red & 0.73 & 0.14 & 0.81 & -0.09 & 0.77 & 0.01 \\
& NIR & 0.86 & -0.05 & 0.87 & -0.06 & 0.87 & 0.04 \\
\hline & Red & 0.75 & -0.15 & 0.80 & -0.10 & 0.79 & 0.01 \\
& NIR & 0.87 & -0.06 & 0.87 & -0.07 & 0.88 & 0.04 \\
\hline \multirow{2}{*}{$35 \%, \leq 50 \%$} & Red & 0.68 & -0.16 & 0.80 & -0.10 & 0.77 & 0.01 \\
& NIR & 0.83 & -0.06 & 0.87 & -0.07 & 0.86 & 0.04 \\
\hline \multirow{2}{*}{$>50 \%, \leq 65 \%$} & Red & 0.71 & -0.16 & 0.78 & -0.10 & 0.78 & 0.01 \\
& NIR & 0.85 & -0.07 & 0.87 & -0.07 & 0.87 & 0.04 \\
\hline \multirow{2}{*}{$>65 \%, \leq 80 \%$} & Red & 0.70 & -0.17 & 0.78 & -0.11 & 0.76 & 0.02 \\
& NIR & 0.85 & -0.07 & 0.87 & -0.07 & 0.85 & 0.04 \\
\hline \multirow{2}{*}{$>80 \%, \leq 95 \%$} & Red & 0.71 & -0.18 & 0.76 & -0.11 & 0.74 & 0.02 \\
& NIR & 0.84 & -0.08 & 0.86 & -0.07 & 0.84 & 0.04 \\
\hline \multirow{2}{*}{$>95 \%$} & Red & 0.71 & -0.24 & 0.74 & -0.11 & 0.72 & 0.03 \\
& NIR & 0.84 & -0.09 & 0.83 & -0.08 & 0.80 & 0.04 \\
\hline
\end{tabular}

\subsection{Vegetation Index Time Series Analysis}

Since the resulting ESTARFM predicted red and NIR bands were of good quality, the data were used to calculate ESTARFM NDVI time series suitable for comparison to NDVI time series derived from RapidEye images. No temporal filtering was applied. Figure 6A,B show ESTARFM and RapidEye NDVI time series derived from averaging all pixels at RapidEye resolution found within MODIS pixel size extents that contain less than $5 \%$ bush cover, with the corresponding error bars representing the standard deviation. The general behaviour of the vegetation dynamics captured by the time series coincides visually well over time for both subsets. NDVI values for grass cover were low (around 0.23) during the southern hemisphere winter and spring months (June to November). At this time, green cover was little and ground cover comprised considerable amounts of standing dead material of senescent grasses, causing decreases in NDVI values [35]. NDVI values increased during the summer months from December to February, indicating a growing period induced by increased rainfall and higher temperatures, reaching its peak in late summer to early autumn (February-March, with NDVI values around 0.36 up to 0.4 ). This period was followed by a steady decline of NDVI values in autumn (drying off period lasting from March to May), eventually reaching values of the preceding year.

RapidEye time series show a time of maximum NDVI at a later point than that captured by the ESTARFM series. The RapidEye time series displaying the vegetation dynamics consist of 15 and 16 images respectively, captured between June 2011 and July 2012 and thus exhibit a high temporal resolution. However, a lengthy gap occurs between February and April 2012 (with the bracketing scenes captured on 11 February 2012 and 19/22 April 2012), resulting in a uniform increase of NDVI values between the dates. Contrary, the ESTARFM time series suggests a sudden drop followed by vegetation regrowth, indicating an unknown process that took place and was not captured by the RapidEye time series alone. The original MODIS images were checked, and did not show signs of disturbance, such as 
fire or dust. The variability in standard deviations of NDVI values is low in both the RapidEye and ESTARFM time series during times of low dynamics. Higher standard deviations can be observed during increment, peak and decrement of the curve, with ESTARFM showing higher deviations than RapidEye during the vegetation growth. Corresponding to Figure 6, Figure 7A,B depict a comparison of NDVI time series derived from RapidEye and ESTARFM averaged pixels falling into MODIS pixel sized cells classified as $>95 \%$ of bush cover.

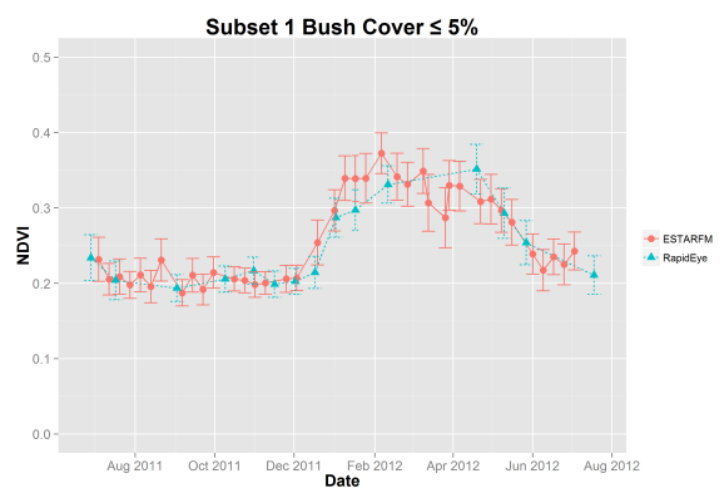

(A)

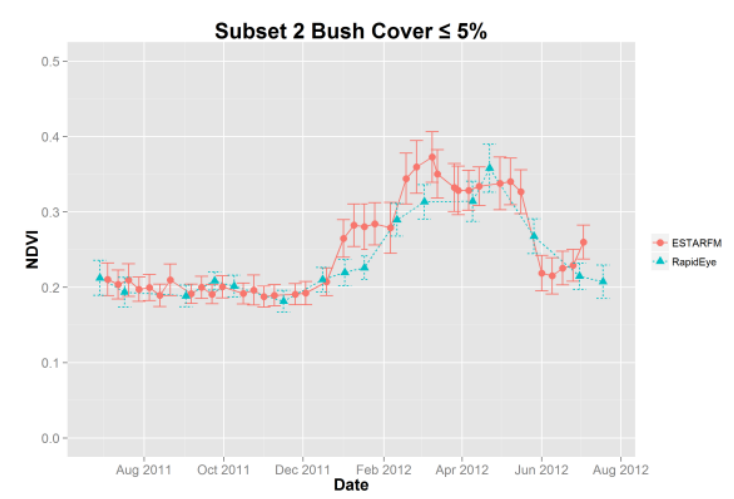

(B)

Figure 6. Time series of mean NDVI values calculated for all MODIS pixel size extents classified as containing $\leq 5 \%$ bush cover, derived from RapidEye and synthetic ESTARFM imagery. The error bars represent the standard deviation. (A) subset 1; (B) subset 2.

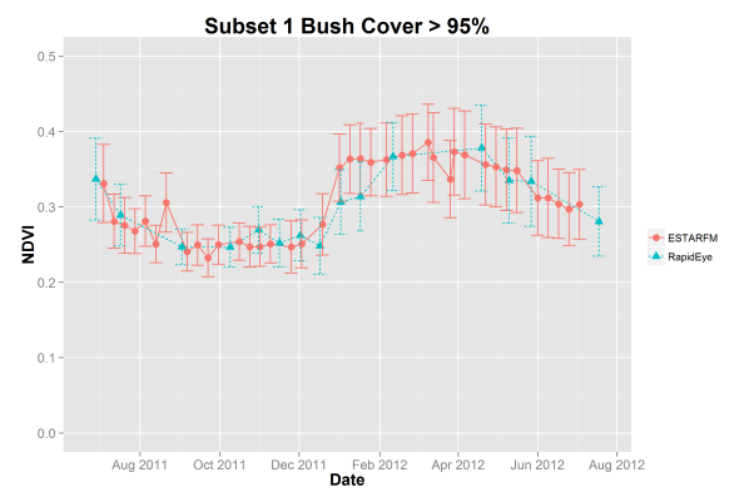

(A)

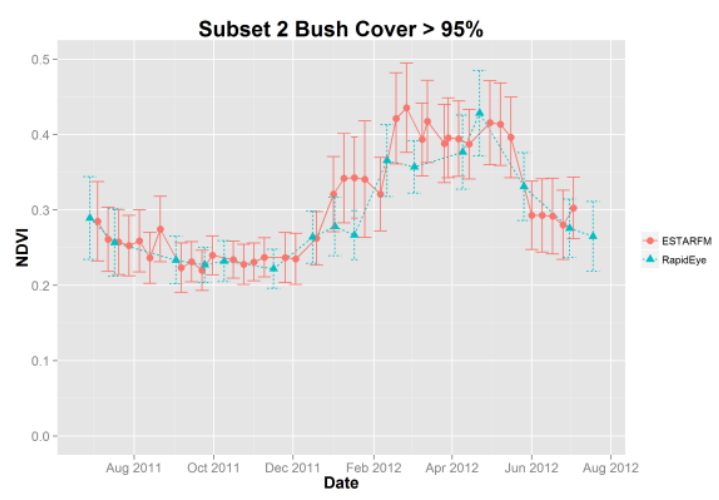

(B)

Figure 7. Time series of mean NDVI values calculated for all MODIS pixel size extents classified as containing $>95 \%$. See Figure 6 for detailed description of sub-plots. (A) subset 1 ; (B) subset 2.

The period of low NDVI values is short, suggesting a dry period that lasts only from September to November 2011. With values around 0.26, values are comparably higher than at grass-dominated sites. According to Wagenseil and Samimi [32], higher values result from higher amounts of dry matter. This is followed by a period of NDVI increase (December to February), with its peak occurring simultaneously to grass covered sites. A decrease can be seen as of spring, with differences exhibited by the time series. Generally, the decline in green cover at bush-dominated sites occurs slower than at 
grass-dominated sites. The dip in NDVI values in February 2012 followed by an increase can be observed in the ESTARFM time series, but not in the RapidEye one (Figure 7A,B).

And again, variability in standard deviations is low during times of no growth, but shows a discrepancy in phases of vegetation greening. Figure 8A,B shows a comparison of NDVI time series for the averages of those pixels falling into MODIS pixels containing mixed vegetation communities, with a percentage of area of bush cover between $>50 \%$ and $\leq 65 \%$. Despite the heterogeneity, the overall compliance of the ESTARFM and RapidEye NDVI time series is good. The curves feature all characteristics that are mentioned above, in connection with the NDVI values found in homogeneous areas. Standard deviations exhibit similar dimensions during phases of non-dynamics, and diverge during times of vegetation growth.

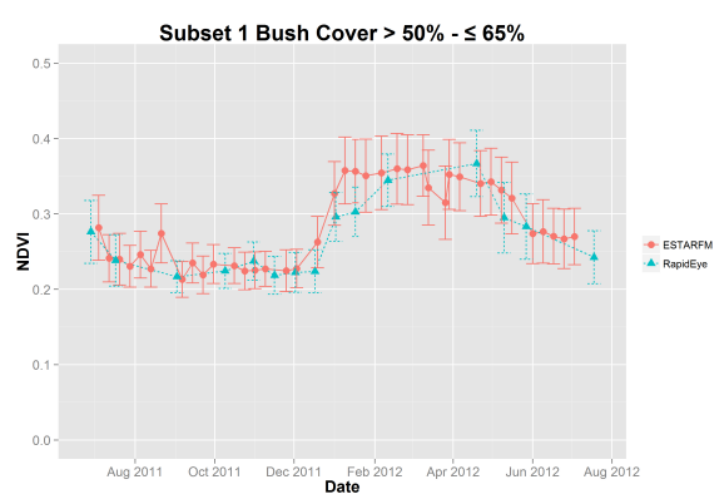

(A)

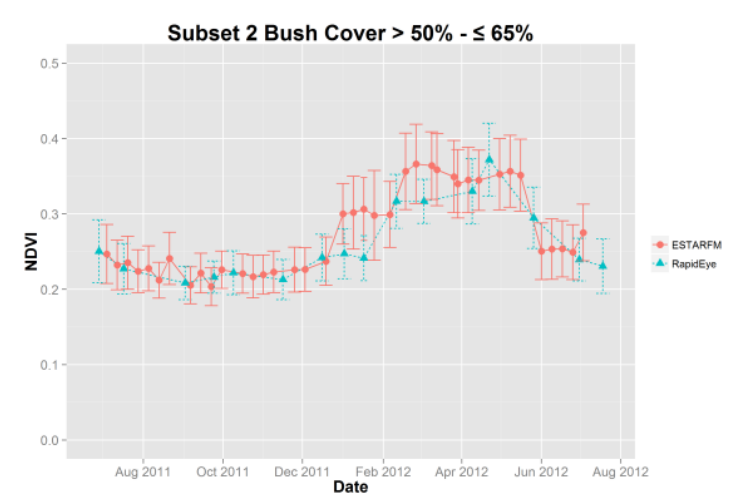

(B)

Figure 8. Time series of mean NDVI values calculated for all MODIS pixel size extents classified as containing $>50 \%$ and $\leq 65 \%$ bush cover. See Figure 6 for detailed description of sub-plots. (A) subset 1; (B) subset 2.

\section{Discussion}

\subsection{Band Differences}

We found strong correlations between the observed and predicted RapidEye reflectance values, for both the red and NIR bands ( $R^{2}$ values range from 0.80 to 0.92 for the red band and from 0.83 to 0.93 for the NIR band). Results suggest that precision is best during phases of low vegetation dynamics, and deteriorates during phases of strong vegetation growth (December, January). Notably, predictions generally achieved better results for the NIR band than for the red band. This may be because the reflected radiation in the NIR is higher for vegetated land surfaces than in the visible wavelength and hence proportionally less affected by radiation variations. Roy et al. [36], using a different fusion approach with MODIS and Landsat imagery, observed the same behaviour in their study. They attribute this to greater influence of atmospheric effects at shorter wavelengths. Rayleigh scattering affects shorter wavelength more seriously than longer wavelengths [37], and aerosol scattering is frequently more significant at shorter wavelengths [36]. These findings are also confirmed by Hilker et al. [11], who found STARFM predictions of shorter wavebands to be less precise than those made for the NIR region at a coniferous dominated study site in central British Columbia, Canada. Contrary, Walker et al. [10] observed higher $R^{2}$ values for the red band than for the NIR band, using STARFM to create synthetic 
imagery for semi-arid dryland forest and grassland in central Arizona, USA. This suggests that further testing of the fusion method is needed for a range of sensors/environmental settings to enable the application value of this approach.

Although we carefully masked out cloud pixels in the RapidEye images, remaining deviating pixel values might have affected ESTARFM predictions and results of the accuracy assessment, caused by variations in aerosol loadings and water vapour variations not taken into account by the atmospheric correction procedure. Furthermore, Schmidt et al. [8] found that erroneous MODIS flag files and data gaps in the MODIS 8-day image product caused outlying STARFM prediction values. This could be as well the case in our study.

In almost all cases, the relative mean bias was not equal to 0 , with sets of both positive and negative numbers. We interpret this to be noise likely due to atmospheric and BRDF effects. These results were also found in the studies by Gao et al. [9]; Hilker et al. [11] and Singh [38].

The bias is a global measurement criterion where the location of the pixel value is not taken into account. On the contrary, the per-pixel level of error and coefficient of determination are criteria very sensitive to value changes in the pixel location [31]. A low $R^{2}$, high per-pixel level of error and a bias of close to zero would thus mean that pixel values in their location have changed, but the overall distribution of values has not. This might have occurred in the predicted image dated 09 January 2012, as the relative mean bias is comparatively low (0.02 and -0.01), but the per-pixel level of error is high (0.07 and 0.07) and $R^{2}$ is low (0.84 and 0.83 ). Visual inspection of the input MODIS image, however, did not reveal any deviations. The band by band comparison of observed and predicted images for different bush density classes shows strong relationships, suggesting a good performance of ESTARFM at sub-MODIS scale. Overall, $R^{2}$ values are lower than those found in the accuracy assessment conducted for the entire image, indicating a decline in quality over vegetated areas.

\subsection{Evaluation of NDVI Time Series}

The comparison of the NDVI time series derived from ESTARFM and RapidEye data shows that the ESTARFM-predicted temporal sequence reproduces the characteristic phenological dynamics of different vegetation communities well. The good agreement of RapidEye and ESTARFM-derived curves for heterogeneous vegetation cover (bush cover between $50 \%$ and 65\%) indicates good prediction behaviour at MODIS sub-pixel scale. This assumption is supported by the good correlations found, although it shows a decline in prediction accuracy with increasing bush density. The comparison furthermore indicated that the fusion approach provides additional information that would not have been captured by either MODIS or RapidEye series alone. This is remarkable, because the time series derived from RapidEye data already contains information from 15 (Subset 1) and 16 (Subset 2) images respectively, throughout a period of 12 months. However, the ability to predict changes in the fine-resolution images depends on the capacity of MODIS to capture these changes. If they are too subtle to be captured, particularly when originating from vegetation structure, stand composition or at sub-pixel ranges, no algorithm will be able to predict any changes $[9,11]$.

Generally, the NDVI is subject to known and well-documented limitations, such as soil coverage and soil moisture effects on rangelands and its spatial discontinuity. Additionally, the signal may be hindered by noise arising from varying atmospheric conditions (such as clouds, ozone, dust and other aerosols) 
and sun-sensor-surface viewing geometries. A broad variety of strategies, such as data smoothing techniques, exist to reduce the impacts of these issues [39].

\subsection{BRDF Effects}

The MODIS MOD09GQ product is generated by selecting pixels matching different criteria from a number of images collected over a period of 8 days, preferably those taken at a low viewing angle, which minimizes angular effects. In some images, the reflectance values for adjacent pixels were collected at different illumination intensities and at different viewing angles and so are subject to high differences. BRDF effects may also explain the oscillating behaviour of the MODIS time series curve in Figure 5. Furthermore, the seasonal devolution of the MODIS offset could be caused by these effects. The time series derived from RapidEye data, whose images are also prone to effects caused by different illumination and viewing angles (but to a lesser extent due to the swath width of $77 \mathrm{~km}$ only), shows less amplitude, indicating a good performance of the atmospheric correction algorithm. However, the usage of the NDVI should limit the impact of directional effects, as the signatures in the red and NIR are quite similar [40]. Walker et al. [10] evaluated the effect of BRDF-adjustment on the accuracy of fused MODIS-Landsat imagery using STARFM. They found that for NDVI the 8-day composite results were similar to those of the Nadir BRDF-Adjusted Reflectance (NBAR) 16-day composite data, indicating that compositing effects only play a minor role for the derivation of indices. The impact of angular effects on the results is an important topic for a consequent study and could be addressed via radiative transfer modelling or by using a simple model based on BRDF parameters [40]. To enhance usability and practical value of medium resolution datasets from MODIS, either BRDF correction should be inherently included in these products or operational automated tools for BRDF correction should be developed by the image providers.

\subsection{Co-Registration of MODIS and RapidEye Images}

We relied on the georeferences provided with the MODIS and RapidEye data. This might have introduced an error of unknown extent in case good sub-pixel alignment was not achieved between the datasets. However, the investigation of errors caused by insufficient co-registration was beyond the scope of this study, but may offer a foundation for further research. We furthermore assume that ESTARFM's moving window is able to reduce the effect of co-registration error to some extent.

\section{Conclusions and Outlook}

The ESTARFM algorithm could successfully be applied for the generation of a high spatio-temporal vegetation time series by fusing RapidEye and MODIS imagery. The ESTARFM prediction accuracy is good for the red and NIR bands during phases of little vegetation dynamics, but deteriorates during times of quick vegetation growth. The NIR band generally yields better prediction results than the red band. ESTARFM algorithm applied to MODIS and RapidEye imagery shows strong prediction performance at sub-MODIS scale in heterogeneous vegetated areas, with best results during phases of low vegetation dynamics. Strategies to reduce noise of NDVI time series may be helpful in future research to reduce errors caused by variations in atmospheric conditions and BRDF effects. 
The ESTARFM derived NDVI time series reproduces the characteristic phenological development of different vegetation types well and inherits more information than either MODIS or RapidEye alone. The derivation of a complete series of high resolution satellite imagery from both real and synthetic RapidEye scenes allows to capture temporal variation of vegetation characteristics estimates throughout the growing season which otherwise cannot be obtained. Due to the combination of large spatial coverage of the sensor with short term observation intervals and fine spatial resolution, the response of vegetation to environmental factors and to management can be much better observed and interpreted. So, employing ESTARFM using the combination RapidEye-MODIS allows for the coverage of spatio-temporal patterns of vegetation dynamics at small scale that must remain undetected without this technique. Our results and conclusions might apply to semi-arid rangelands only. The transferability to other landscapes and vegetation covers can be subject to further studies. An expansion to a longer time series is favourable and may give further insight to small scale trends over long time periods.

\section{Acknowledgments}

This study was carried out as part of the research project "Resilience, Collapse and Reorganisation in Social-Ecological Systems of African Savannas" (FOR 1501), funded by the German Research Foundation (DFG). We thank the DLR for the provision of RapidEye data from the RapidEye Science Archive and for providing access to the CATENA processing system. We are furthermore grateful for partial funding from the German Federal Ministry of Education and Research (BMBF) in the SPACES project "Living Landscapes Limpopo". Thanks to Katharina Brüser for her preceding work.

\section{Author Contributions}

Andreas Tewes prepared the data, performed the analysis and wrote the paper. Frank Thonfeld and Michael Schmidt contributed to the analysis and interpretation of results. Roelof Oomen added knowledge about the study area. Xiaolin Zhu gave valuable help concerning ESTARFM. Olena Dubovyk contributed information about BRDF issues and manuscript preparation. Gunter Menz and Jürgen Schellberg supervised the work and helped structuring the document.

\section{Conflicts of Interest}

The authors declare no conflict of interest.

\section{References}

1. Fensholt, R.; Sandholt, I.; Rasmussen, M.S. Evaluation of MODIS LAI, fAPAR and the relation between fAPAR and NDVI in a semi-arid environment using in situ measurements. Remote Sens. Environ. 2004, 91, 490-507.

2. Pettorelli, N.; Vik, J.O.; Mysterud, A.; Gaillard, J.-M.; Tucker, C.J.; Stenseth, N.C. Using the satellite-derived NDVI to assess ecological responses to environmental change. Trends Ecol. Evol. 2005, 20, 503-510.

3. Reed, B.C.; Brown, J.F.; VanderZee, D.; Loveland, T.R.; Merchant, J.W.; Ohlen, D.O. Measuring phenological variability from satellite imagery. J. Veg. Sci. 1994, 5, 703-714. 
4. Busetto, L.; Meroni, M.; Colombo, R. Combining medium and coarse spatial resolution satellite data to improve the estimation of sub-pixel NDVI time series. Remote Sens. Environ. 2008, 112, 118-131.

5. Aplin, P. Remote sensing: Ecology Prog. Phys. Geogr. 2005, 29, 104-113.

6. Brüser, K.; Feilhauer, H.; Linstädter, A.; Schellberg, J.; Oomen, R. J.; Ruppert, J. C.; Ewert, F. Discrimination and characterization of management systems in semi-arid rangelands of South Africa using RapidEye time series. Int. J. Remote Sens. 2014, 35, 1653-1673.

7. Watts, J. D.; Powell, S. L.; Lawrence, R. L.; Hilker, T. Improved classification of conservation tillage adoption using high temporal and synthetic satellite imagery. Remote Sens. Environ. 2011, $115,66-75$.

8. Schmidt, M.; Udelhoven, T.; Gill, T.; Röder, A. Long term data fusion for a dense time series analysis with MODIS and Landsat imagery in an Australian Savanna. J. Appl. Remote Sens. 2012, 6, doi:10.1117/1.JRS.6.063512.

9. Gao, F.; Masek, J.; Schwaller, M.; Hall, F. On the blending of the Landsat and MODIS surface reflectance: Predicting daily Landsat surface reflectance. IEEE Trans. Geosci. Remote Sens. 2006, 44, 2207-2218.

10. Walker, J.J.; de Beurs, K.M.; Wynne, R.H.; Gao, F. Evaluation of Landsat and MODIS data fusion products for analysis of dryland forest phenology. Remote Sens. Environ. 2012, 117, 381-393

11. Hilker, T.; Wulder, M.A.; Coops, N.C.; Seitz, N.; White, J.C.; Gao, F.; Masek, J.G.; Stenhouse, G. Generation of dense time series synthetic Landsat data through data blending with MODIS using a spatial and temporal adaptive reflectance fusion model. Remote Sens. Environ. 2009, 113, 1988-1999.

12. Zhu, X.; Chen, J.; Gao, F.; Chen, X.; Masek, J.G. An enhanced spatial and temporal adaptive reflectance fusion model for complex heterogeneous regions. Remote Sens. Environ. 2010, 114, 2610-2623.

13. Kim, J.; Hogue, T.S. Evaluation and sensitivity testing of a coupled Landsat-MODIS downscaling method for land surface temperature and vegetation indices in semi-arid regions. J. Appl. Remote Sens. 2012, 6, doi:10.1117/1.JRS.6.063569.

14. Pohl, C.; van Genderen, J.L. Review article Multisensor image fusion in remote sensing: Concepts, methods and applications. Int. J. Remote Sens. 1998, 19, 823-854.

15. Hansen, M.C.; Roy, D.P.; Lindquist, E.; Adusei, B.; Justice, C.O.; Altstatt, A. A method for integrating MODIS and Landsat data for systematic monitoring of forest cover and change in the Congo Basin. Remote Sens. Environ. 2008, 112, 2495-2513.

16. Walker, J.J.; de Beurs, K.M.; Wynne, R.H. Dryland vegetation phenology across an elevation gradient in Arizona, USA, investigated with fused MODIS and Landsat data. Remote Sens. Environ. 2014, 144, 85-97.

17. Emelyanova, I.V.; McVicar, T.R.; Niel, T.G.V.; Li, L.T.; van Dijk, A.I.J.M. Assessing the accuracy of blending Landsat-MODIS surface reflectances in two landscapes with contrasting spatial and temporal dynamics: A framework for algorithm selection. Remote Sens. Environ. 2013, 133, 193-209.

18. Zhang, F.; Zhu, X.; Liu, D. Blending MODIS and Landsat images for urban flood mapping. Int. J. Remote Sens. 2014, 35, 3237-3253. 
19. Schmidt, M.; Lucas, R.; Bunting, P.; Verbesselt, J.; Armston, J. Multi-resolution time series imagery for forest disturbance and regrowth monitoring in Queensland, Australia. Remote Sens. Environ. 2015, 158, 156-168.

20. Settle, J.J.; Drake, N.A. Linear mixing and the estimation of ground cover proportions. Int. J. Remote Sens. 1993, 14, 1159-1177.

21. Mucina, L.; Rutherford, M.C. The Vegetation of South Africa, Lesotho and Swaziland; South African National Biodiversity Institute: Pretoria, South Africa, 2006.

22. Van Rooyen, N.; Bezuidenhout, H.; De Kock, E. Flowering plants of the Kalahari dunes; Ekotrust: Pretoria, South Africa, 2001.

23. Palmer, A.R.; Ainslie, A.M. Grasslands of South Africa. In Grasslands of the World; Suttie, J.M., Reynolds, S.G., Batello, C., Eds.; Food and Agriculture Organization of the United Nations: Rome, Italy, 2005; pp. 77-120.

24. Trodd, N.M.; Dougill, A.J. Monitoring vegetation dynamics in semi-arid African rangelands: Use and limitations of Earth observation data to characterize vegetation structure. Appl. Geogr. 1998, 18, 315-330.

25. Tyc, G.; Tulip, J.; Schulten, D.; Krischke, M.; Oxfort, M. The RapidEye mission design. Acta Astronaut. 2005, 56, 213-219.

26. RapidEye AG Satellite Imagery Product Specifications, Version 4.1. Available online: http://www.gisat.cz/images/upload/c1626_rapideye-image-product-specs-april-07.pdf (accessed on 2 September 2014)

27. Krauß, T.; d' Angelo, P.; Schneider, M.; Gstaiger, V. The fully automatic optical processing system CATENA at DLR. Int. Arch. Photogramm. Remote Sens. Spat. Inf. Sci. 2013, XL-1/W1, 177-183.

28. Richter, R.; Schläpfer, D. Atmospheric/Topographic Correction for Satellite Imagery: ATCOR-2/3 User Guide, Version 8.2.3; ReSe Applications Schlapfer: Langeggweg, Switzerland, 2012.

29. MODIS MOD09Q1 Product Description. Available online: https://lpdaac.usgs.gov/ products/modis_products_table/mod09q1 (accessed on 21 May 2015).

30. Wald, L.; Ranchin, T.; Mangolini, M. Fusion of satellite images of different spatial resolutions: Assessing the quality of resulting images. Photogramm. Eng. Remote Sens. 1997, 63, 691-699.

31. Thomas, C.; Wald, L. Comparing distances for quality assessment of fused images. In New Developments and Challenges in Remote Sensing; Bochenek, E., Ed.; Millpress: Varsovie, Poland, 2007; pp. 101-111.

32. Wagenseil, M.; Samimi, C. Woody vegetation cover in Namibian savannahs: A modelling approach based on remote sensing. Erdkunde 2007, 61, 325-334.

33. Scholes, R.J.; Walker, B.H. An African Savanna: Synthesis of the Nylsvley Study; Cambridge University Press: Cambridge, UK, 1993.

34. Schmidt, H.; Karnieli, A. Remote sensing of the seasonal variability of vegetation in a semi-arid environment. J. Arid Environ. 2000, 45, 43-59.

35. Weiss, J.L.; Gutzler, D.S.; Coonrod, J.E.A.; Dahm, C.N. Long-term vegetation monitoring with NDVI in a diverse semi-arid setting, central New Mexico, USA. J. Arid Environ. 2004, 58, 249-272.

36. Mather, P.M. Computer Processing of Remotely-Sensed Images, 3rd ed.; John Wiley \& Sons, Ltd: Chichester, UK, 2004. 
37. Roy, D.P.; Ju, J.; Lewis, P.; Schaaf, C.; Gao, F.; Hansen, M.; Lindquist, E. Multi-temporal MODIS-Landsat data fusion for relative radiometric normalization, gap filling, and prediction of Landsat data. Remote Sens. Environ. 2008, 112, 3112-3130.

38. Singh, D. Evaluation of long-term NDVI time series derived from Landsat data through blending with MODIS data. Atmósfera 2012, 25, 43-63.

39. Hird, J.N.; McDermid, G.J. Noise reduction of NDVI time series: An empirical comparison of selected techniques. Remote Sens. Environ. 2009, 113, 248-258.

40. Bréon, F.-M.; Vermote, E. Correction of MODIS surface reflectance time series for BRDF effects. Remote Sens. Environ. 2012, 125, 1-9.

(C) 2015 by the authors; licensee MDPI, Basel, Switzerland. This article is an open access article distributed under the terms and conditions of the Creative Commons Attribution license (http://creativecommons.org/licenses/by/4.0/). 